Original Research Article

\title{
Drug use in acute otitis media: a prospective study at a tertiary care teaching hospital
}

\author{
Rushi N. Pandya ${ }^{1}$, Maulik M. Patel ${ }^{2 *}$, Varsha J. Patel ${ }^{2}$
}

\begin{abstract}
${ }^{1}$ Department of Clinical
Research, Torrent Research

Centre, Ahmedabad, Gujarat,

India

${ }^{2}$ Department of Pharmacology,

Dr. M. K. Shah Medical College and Research Centre,

Chandkheda, Ahmedabad,

Gujarat, India
\end{abstract}

Received: 25 November 2018

Accepted: 28 December 2018

*Correspondence to:
Dr. Maulik M. Patel,
Email: patelmaulik24@
gmail.com

Copyright: (C) the author(s), publisher and licensee Medip Academy. This is an openaccess article distributed under the terms of the Creative Commons Attribution NonCommercial License, which permits unrestricted noncommercial use, distribution, and reproduction in any medium, provided the original work is properly cited.

\begin{abstract}
Background: Drug use study identifies the problems that arise from prescription and highlights the current approaches to the rational use of drugs. The objective of the study was to assess drug use pattern in patients diagnosed of acute otitis media in tertiary care teaching hospital.

Methods: This prospective observational study was carried in the Otorhinolaryngology department of a tertiary care teaching hospital over a period of twelve months. The data collected for patients with acute otitis media included the patient's demographic details and the drugs prescribed. Data were analysed for drug use pattern and cost per prescription and assessment of rationality of prescription.

Results: Total 153 patients were analysed, $100(65.35 \%)$ belonged to male patients and $53(34.65 \%)$ belonged to female patients. Children less than 2years age were the most diagnosed with AOM $47.71 \%$, the major diagnostic symptoms were earache $(58.16 \%)$ and fever $(54.90 \%)$ and signs were congestion $(52.94 \%)$ and discharge $(43.13 \%)$. In a total 153 prescriptions (469 drugs), 33.68\% were antimicrobials, followed by mineral supplements $(23.67 \%)$. Average number of drugs per prescription was found to be 3.0. Most common antibiotic prescribed was amoxicillin (with or without clavulanate) in $142(92.81 \%)$ patients. Paracetamol alone or in fixed dose combination with antihistaminics were prescribed in 131 patients. Average cost per prescription was $87.74( \pm 35.67)$ Indian rupees. Seventeen $(11.11 \%)$ prescriptions were rational in all the aspects based on standard guidelines.

Conclusions: The present study showed that paracetamol and amoxicillin with or without clavulanate were mostly commonly prescribed in children with AOM. Irrational prescribing was seen in maximum number of cases.
\end{abstract}

Keywords: Acute otitis media, Drug use study, Otorhinolaryngology

\section{INTRODUCTION}

Acute Otitis Media (AOM) remains one of the common childhood infections which bring children to doctors though majority of cases are self-limiting. ${ }^{1}$ Almost all children experience at least one episode of AOM before school age, but on average will only suffer one or two episodes in total. However, approximately $5 \%$ of children will experience recurrent episodes of AOM, often defined as at least 3 episodes of AOM over a 6-month period or 4 episodes over a year. ${ }^{2}$
Pathophysiologically, AOM is an inflammation in the mucous membrane of the middle ear with the development of a purulent effusion which becomes trapped in the middle ear. ${ }^{3}$ clinically; AOM is defined as a history of acute onset of signs and symptoms of otalgia and fever, the presence of middle ear effusion, and signs and symptoms of middle ear inflammation. ${ }^{4}$

It remains the most common condition for which antimicrobials are prescribed for children in developed countries. A few studies found initial antimicrobials are 
beneficial while others found no statistical significance between initial antimicrobials and placebo in providing symptomatic relief. ${ }^{5,6}$ A study carried out in Canada reveals amoxicillin as the most commonly prescribed antimicrobial followed by cefprozil and azithromycin. ${ }^{7}$ Another study of US national database also found amoxicillin as the most frequently used antimicrobial for AOM. ${ }^{8}$

American Academy of Paediatrics (AAP) guidelines are focussed around key statements relates to diagnosis of the condition by otoscopy and/or tympanometry, assessment of pain, selecting and prescribing antimicrobials, prophylaxis and recommendations regarding to pneumococcal vaccine. These guidelines give recommendations for initial observation with close follow up, initial immediate antibiotic treatment or antibiotic treatment after 48-72hours of onset of symptoms. Antimicrobials effective for AOM includes amoxicillin (with or without clavulanate), azithromycin, clarithromycin and a few cephalosporins like cefdinir, cefopodoxime and ceftriaxone. ${ }^{9}$

Drug utilization research was defined by World Health Organisation (WHO) as "the marketing, distribution, prescription, and use of drugs in a society, with special emphasis on the resulting medical, social and economic consequences." The principal aim of drug utilization research is to facilitate the rational use of drugs in populations. ${ }^{10}$

Most of the countries have their own set of guidelines for diagnosing and treating AOM; the European countries being more inclined towards the Wait and Watch policy than their western counterparts. The lack of Indian guidelines and Indian data for AOM encouraged us to carry out this drug utilization study in order to analyse the prescribing trends and patterns in patients diagnosed of AOM in a tertiary care teaching hospital. However, to our knowledge there is no Indian study which depicts the trends of drugs prescribing in patients diagnosed of AOM. Hence, this study was undertaken with the aim of identifying the prescribing pattern, cost-analysis and to assess the rationality of the prescription in AOM based on standard guidelines given by AAP.

\section{METHODS}

The Otorhinolaryngology outpatient department of Sheth V. S. General Hospital, a tertiary care teaching hospital from December 2011 to November 2012. This was prospective, observational, cross-sectional and single centre study.

\section{Inclusion criteria}

- All age group, male or female patients diagnosed of AOM in the Otorhinolaryngology Department

- And who had given consent for participation was included in the study.

\section{Study method}

Protocol of the study procedure was designed together with the Case Record Form (CRF), Patient Information Sheet (PIS) and Informed Consent Form (ICF). The study began after obtaining the approval from Institutional Review Board (IRB). After taking the written consent of the accompanying guardian (in case of a minor) or the patient (in case of an adult), the data was collected in CRF. The CRF included demographic details, chief complaints, provisional diagnosis, otoscopic findings and the treatment prescribed. Data were entered in Microsoft Excel 2007.

\section{Statistical analysis}

The data were analysed by SPSS v20.0 for demographic characteristics, chief complaints, otoscopic findings of the tympanic membrane, accompanying conditions, frequently prescribed drugs in AOM and the pattern of antimicrobial prescribing, ATC Classification of drugs, rationality of the antimicrobial prescribed based on guidelines given by AAP. ${ }^{9,11}$ Costs of all the prescriptions were calculated in Indian National Rupees (INR) for the entire course of therapy per patient. Mean $( \pm \mathrm{SD})$ was then calculated.

\section{RESULTS}

A total of 153 patients diagnosed of AOM were enrolled in the study during a period of 1 year.

Out of 153 patients, $53(34.65 \%)$ were females; male: female ratio being 1.88:1. $140(91.50 \%)$ out of 153 patients enrolled were under 12 years of age and $73(47.71 \%)$ belonged to the 7-23 months age group. 117 (76.48\%) and $36(23.52 \%)$ patients had unilateral and bilateral involvement of middle ear respectively.

The most common complaint was earache $(89,58.16 \%)$, followed by fever $(84,54.90 \%)$. A combination of fever and earache was experienced by $52(33.98 \%)$ patients. The most common otoscopic finding of tympanic membrane was congestion $(81,52.94 \%)$, followed by discharge $(66$, $43.13 \%)$, bulging $(61,39.86)$, redness $(36,23.52 \%)$ and opacity $(11,7.1 \%)$.

Rhinitis (69, 45.09\%) was the most common condition associated with AOM followed by pharyngitis (27, $17.64 \%$ ). Both rhinitis and pharyngitis were observed in 8 $(5.22 \%)$ patients.

A total of 469 drugs were prescribed in 153 prescriptions, average being $3.07 \pm 0.60$ drugs per prescription. Of the 469 drugs prescribed, $33.68 \%$ were antimicrobials, followed by mineral supplements $(23.67 \%)$ and analgesics $(8.74 \%)$ according to ACT classification of drug groups (Table 1).

Paracetamol was prescribed in 131 patients, out of which $90(68.70 \%)$ received it as fixed dose combination with other drugs. Fixed dose combination of paracetamol, 
phenylephrine and chlorpheniramine was given in 82 patients. But paracetamol in combinations was not mentioned in the ATC classification. Second most commonly prescribed drug was amoxicillin in 124 patients followed by zinc sulfate in 111 patients.

Table 1: Prescribed drug group $(n=153)$.

\begin{tabular}{|ll|}
\hline $\begin{array}{l}\text { ATC Classification of drug } \\
\text { group }\end{array}$ & $\%$ of total drugs \\
\hline Antibacterials (J01) & $33.68 \%$ \\
\hline Mineral supplements (A12C) & $23.67 \%$ \\
\hline Analgesics (N02B) & $8.74 \%$ \\
\hline PPIs (A02B) & $3.41 \%$ \\
\hline Antihistaminics (R06A) & $2.13 \%$ \\
\hline Multivitamins (A11A) & $1.91 \%$ \\
\hline Anti-inflammatory (M01A) & $0.85 \%$ \\
\hline Antifungals (D01B) & $0.42 \%$ \\
\hline
\end{tabular}

Among antimicrobials, amoxicillin $(124,81.04 \%)$ was the most commonly prescribed, followed by amoxicillinclavulanate $(18,11.76 \%)$. Seven patients $(4.5 \%)$ were prescribed 2 antimicrobials (Table 2).
Table 2: Pattern of antimicrobial prescribing in $\operatorname{AOM}(\mathbf{n}=153)$.

\begin{tabular}{|ll|}
\hline Antimicrobials & No. of patients \\
\hline Amoxicillin & 124 \\
\hline Amoxicillin-clavulanate & 18 \\
\hline Azithromycin & 5 \\
\hline Doxycycline & 4 \\
\hline Norfloxacin & 4 \\
\hline Cefuroxime & 3 \\
\hline Clotrimazole & 2 \\
\hline
\end{tabular}

The average cost per prescription for patients diagnosed of acute otitis media was Rs. 87.74 \pm 35.67 Indian rupees; range being Rs. 17.12 to Rs. 276 .

Thirty three $(21.56 \%)$ patients were misdiagnosed to be suffering from AOM. The antimicrobial was under prescribed with respect to both dose and duration in $31.38 \%$ and $79.74 \%$ patients respectively. Seventeen $(11.11 \%)$ prescriptions were rational in all the aspects (Table 3).

Table 3: Rationality of the prescriptions $(n=153)$.

\begin{tabular}{|llllll|}
\hline & Based on & Selection of & Dose of \\
& $\begin{array}{l}\text { Diagnostic } \\
\text { rationality }\end{array}$ & $\begin{array}{l}\text { antimicrobial } \\
\text { antimicrobial }\end{array}$ & $\begin{array}{l}\text { Duration of } \\
\text { antimicrobial }\end{array}$ & $\begin{array}{l}\text { Overall } \\
\text { rationality }\end{array}$ \\
\hline Rational (no.) & 120 & 149 & 105 & 31 & 17 \\
\hline \% Rational & $78.43 \%$ & $97.38 \%$ & $68.62 \%$ & $20.26 \%$ & $11.11 \%$ \\
\hline
\end{tabular}

\section{DISCUSSION}

The peak incidence of AOM was found to be in the age group 1-4years in study carried out in Nigeria. ${ }^{12}$ In present study Majority of patients belonged to 7-23 months of age.

Bulging of the tympanic membrane is highly associated with the presence of a bacterial pathogen, with or without a concomitant viral pathogen. ${ }^{13}$ In our study, the most common otoscopic finding was congestion, followed by recent onset otorrhoea and bulging of the tympanic membrane.

Earache is the only symptom with sufficient positive predictive value to be useful in the diagnosis of AOM. ${ }^{9}$ Almost $60 \%$ of the patients had earache as a presenting symptom in one of the Finnish study. ${ }^{14}$ Earache was present in more than $58 \%$ of patients in this study.

Pain associated with AOM can be severe and often persists for a longer duration in younger children. A study shows persistence of pain or fever or both even after 3-7 days in $30 \%$ of patients younger than 2 years of age who were only on antimicrobials therapy. ${ }^{15}$
Analgesics do relieve pain associated with AOM within 24hours and should be used whether or not antimicrobial is prescribed; and they should be continued as long as needed. ${ }^{9}$ In present study, paracetamol was prescribed in $131(85.62 \%)$ patients either singly or as a fixed dose combination with other drugs irrespective of whether pain was present or not.

Decongestants (with or without antihistaminics) were a popular treatment of AOM, but clinical trials have found no efficacy of these treatments. ${ }^{16}$ In current study, these drugs were prescribed in $98(64.05 \%)$ patients, which may be unnecessary.

In one of the recent trials for assessing the efficacy of zinc in AOM, $62.1 \%$ children had clinical improvement with zinc compared to $43.5 \%$ in the placebo group which was statistically significant. ${ }^{17}$ In present study, $111(72.54 \%)$ patients received topical zinc sulphate; though it has not been mentioned in the guidelines given by AAP.

A clinically significant benefit of immediate antimicrobial therapy is observed for bilateral disease, S. pneumonia infection and AOM associated with otorrhoea. ${ }^{15}$ Clinicians should prescribe amoxicillin in the dose of 80- 
$90 \mathrm{mg} / \mathrm{kg} /$ day in divided doses for AOM when a decision to treat with antibiotics has been made according to AAP. ${ }^{9}$ The most commonly prescribed antimicrobial in our study was amoxicillin (with or without clavulanate) which was prescribed in $92.81 \%$ patients. Antimicrobials were prescribed to all the patients in our study, primarily because of the fear that the patient may not visit the facility again, which is very true for a developing country like India where a majority of population belong to the lower socioeconomic strata.

The average number of drugs used in each prescription was 3. Thus, each prescription might contain an antibiotic, an antihistamine/ analgesics and zinc on an average. The mean cost per prescription was 87.74 Indian Rupees which is quite reasonable and may be because of hospital supply of drugs.

Total $21.5 \%$ patients did not meet the diagnostic criteria but were diagnosed for the AOM. This may be due to the stringent diagnostic criteria given by AAP. Amoxicillin was under prescribed with respect to the dose in some cases. For children younger than 2 years, a standard 10-days course of therapy is recommended whereas a 7 days course is equally effective in children 2 to 5 years of age with mild to moderate AOM.

For children 6years and older, a 5 to 7days course is adequate. ${ }^{9}$ In the present study, none of the patients under 2 years were given the therapy for 10days and a few patients of age group 2 to 5years received the drug for 5days only. Considering a combination of diagnostic rationality, rationality of the antimicrobial selection, dose of the antimicrobial and the duration of the therapy, only $11 \%$ prescriptions were rational. The rest were irrational in at least one or more aspects. Antimicrobials were under prescribed with respect to dose and duration which not only leads to failure of therapy but also development of antimicrobial resistance. Lack of standard national guidelines could be one of the important factors responsible for inappropriate prescribing of medications in AOM. Educational interventions to improve prescribing for doctors at different levels may be required.

Limitations of our study was less number of patients and this study was carried out in a tertiary care teaching hospital which was approached by patients of a particular geographic location; so the results cannot be generalized.

\section{CONCLUSION}

The present study showed that paracetamol and amoxicillin with or without clavulanate were mostly commonly prescribed in children with AOM. Irrational prescribing is seen in maximum number of cases as per standard guidelines. Prescription or drug use study acts as a tool to give feedback to clinicians and hospital administration regarding over/ under prescription of drugs, cost-benefit analysis, and rational drug use.
Funding: No funding sources Conflict of interest: None declared

Ethical approval: The study was approved by the Institutional Ethics Committee

\section{REFERENCES}

1. Rosenfeld RM, Kay D. Natural history of untreated otitis media. Laryngoscope. 2003;113(10):1645-7.

2. Ingvarsson L, Lundgren K. Penicillin treatment of acute otitis media in children. A study of the duration of treatment. Acta Otolaryngol. Sep-Oct 1982;94(34):283-7.

3. Grijalva CG, Nuorti JP, Griffin MR. Antibiotic prescription tares for acute respiratory tract infections in US ambulatory settings. JAMA. 2009;302(7):75866.

4. Fong IW. Emerging Issues and Controversies in Infectious Diseases. New York, NY Springer Science + Business Media, LCC. 2009:36-41.

5. Sanders S, Glasziou PP, DelMar C, Rovers M. Antibiotics for acute otitis media in children (review). Cochrane Database Sys Rev. 2009;(2):1-43.

6. Burke P, Bain J, Robinson D, Dunleavey J. Acute red ear in children: controlled trial of nonantibiotic treatment in children: controlled trial of nonantibiotic treatment in general practice. BMJ. 1991;303(6802):558-62.

7. Quach C, Collet JP, LeLorier J. Acute otitis media in children: a retrospective analysis of physician prescribing patterns. Br J Clin Pharmacol. 2004 Apr; 57(4):500-5.

8. Sidell D, Shapiro NL, Bhattacharyya N. Demographic influences on antibiotic prescribing for pediatric acute otitis media. Otolaryngol Head Neck Surg. 2012 Apr; 146(4):653-8.

9. Lieberthal AS, Carroll AE, Chonmaitree T, Ganiats TG, Hoberman A, Jackson MA, et al. The diagnosis and management of acute otitis media. Pediatrics. 2013 Mar;131(3):e964-99.

10. World Health Organization. Introduction to Drug Utilization Research, 2003. Available at: http://apps.who.int/medicinedocs/pdf/s4876e/s4876e. pdf.

11. WHO Collaborating Centre for Drug Statistics Methodology, Norwegian Institute of Public Health. Guidelines for ATC classification and DDD assignment, 2013. Available at: https://www.whocc.no/filearchive/publications/1_201 3 guidelines.pdf.

12. Amusa YB, Ogunniyi TA, Onayade OO, Okeowo PA. Acute Otitis media, malaria and pyrexia in the under five age group. West African J Med. 2005;24(3):23941.

13. McCormick DP, Chonmaitree T, Pittman C, Saeed K, Friedman NR, Uchida T, et al. Nonsevere acute otitis media: a clinical trial comparing outcomes of watchful waiting versus immediate antibiotic treatment. Pediatrics. 2005 Jun; 115(6):1455-65. 
14. Heikkinen T, Ruuskanen O. Signs and symptoms predicting acute otitis media. Arch Pediatr Adolescent Med. 1995 Jan 1;149(1):26-9.

15. Rovers MM, Glasziou P, Appelman CL, Burke P, McCormick DP, Damoiseaux RA, et al. Antibiotics for acute otitis media: a meta-analysis with individual patient data. Lancet. 2006 Oct 21;368(9545):1429-35.

16. Dusdieker LB, Smith G, Booth BM, Woodhead JC, Milavetz $\mathrm{G}$. The long-term outcome of nonsuppurative otitis media with effusion. Clinical Pediatrics. 1985 Apr;24(4):181-6.
17. Izadi P, Yarmohammadi ME, Kholdi N, Izadi B, Anari $\mathrm{S}$, Sedehi M. Effect of oral supplementation of zinc on treatment of otitis media with effusion. Med J Islamic Republic Iran. 2010 Nov 15;24(3):126-32.

Cite this article as: Pandya RN, Patel MM, Patel VJ. Drug use in acute otitis media: a prospective study at a tertiary care teaching hospital. Int J Basic Clin Pharmacol 2019;8:240-4. 